\title{
Ticks infesting domestic dogs in the UK: a large-scale surveillance programme
}

\author{
Swaid Abdullah ${ }^{1 *}$, Chris Helps ${ }^{2}$, Severine Tasker ${ }^{2}$, Hannah Newbury ${ }^{3}$ and Richard Wall ${ }^{1}$
}

\begin{abstract}
Background: Recent changes in the distribution of tick vectors and the incidence of tick-borne disease, driven variously by factors such as climate change, habitat modification, increasing host abundance and the increased movement of people and animals, highlight the importance of ongoing, active surveillance. This paper documents the results of a large-scale survey of tick abundance on dogs presented to veterinary practices in the UK, using a participatory approach that allows relatively cost- and time-effective extensive data collection.

Methods: Over a period of 16 weeks (April-July 2015), 1094 veterinary practices were recruited to monitor tick attachment to dogs and provided with a tick collection and submission protocol. Recruitment was encouraged through a national publicity and communication initiative. Participating practices were asked to select five dogs at random each week and undertake a thorough, standardized examination of each dog for ticks. The clinical history and any ticks were then sent to the investigators for identification.

Results: A total of 12,000 and 96 dogs were examined and 6555 tick samples from infested dogs were received. Ixodes ricinus (Linnaeus) was identified on 5265 dogs (89 \%), Ixodes hexagonus Leach on 577 (9.8\%) and Ixodes canisuga Johnston on 46 (0.8\%). Ten dogs had Dermacentor reticulatus (Fabricius), one had Dermacentor variabilis (Say), three had Haemaphysalis punctata Canesteini \& Fanzago and 13 had Rhipicephalus sanguineus Latreille. 640 ticks were too damaged for identification. All the $R$. sanguineus and the single $D$. variabilis were on dogs with a recent history of travel outside the UK. The overall prevalence of tick attachment was $30 \%$ (range 28-32\%). The relatively high prevalence recorded is likely to have been inflated by the method of participant recruitment.
\end{abstract}

Conclusion: The data presented provide a comprehensive spatial understanding of tick distribution and species abundance in the UK against which future changes can be compared. Relative prevalence maps show the highest rates in Scotland and south west England providing a valuable guide to tick-bite risk in the UK.

Keywords: Tick, Surveillance, Relative risk, Vector, Ixodes, Dermacentor, Rhipicephalus

\section{Background}

Ticks are globally important arthropod vectors of disease that transmit an extensive range of viral, bacterial and protozoan pathogens to vertebrate hosts [1]. Tick survival, phenology and biting activity is highly dependent on environmental conditions [2] and is highly responsive to changes in factors such as climate and habitat modification. Long-term increases in the abundance of ticks, such as Ixodes ricinus (Linneaus), have been recorded in temperate habitats over recent decades [3], along with evidence of altitudinal and latitudinal expansion in

\footnotetext{
* Correspondence: swaid.abdullah@bristol.ac.uk

'Veterinary Parasitology and Ecology Group, School of Biological Sciences,

Life Sciences Building, University of Bristol, Bristol, UK

Full list of author information is available at the end of the article
}

central and northern Europe [4-8]. Data collected by questionnaire from 20 districts in Sweden showed a significant increase in tick abundance in west-central regions where previously ticks had been rare. Blanket dragging in 54 regions along the perceived latitudinal boundary for ticks supported this observation $[9,10]$. Similarly, in the UK, over recent decades there has been an estimated $17 \%$ expansion in the distribution of I. ricinus and an increase in abundance at $73 \%$ of locations surveyed [11]. The tick Dermacentor reticulatus (Fabricius), an important vector of canine babesiosis in Europe, is also believed to have extended its distribution and populations have become established in Poland [12], Belgium [13], Germany [14], the Netherlands [15] and in southern 
England [16, 17]. Changes in tick-borne disease prevalence are also reported, in association with the changes in vector distribution $[18,19]$.

Climate change is considered likely to be responsibe in part for these observed changes [20] and further climaterelated impacts might be expected if predicted increases in global temperatures of up to $4.8{ }^{\circ} \mathrm{C}$ in the next hundred years occur [21]. Longer summer seasons, with a warmer and wetter spring or autumn, might be expected to promote higher tick challenge and longer exposure. Tick mortality may be lower given milder winters, but higher in hotter drier summers. In addition, vector potential may be enhanced by biological changes stimulated by temperature, as is reported in other arthropod vectors [22]. However, ticks may also adapt their seasonal activity and some species may aestivate during very hot conditions and perhaps adopt a more bimodal pattern of activity, pushing the period of feeding to earlier and later in the year. Nevertheless, along with climate, changes in habitat management, land use by people and animals, host movement patterns and changes in host abundance, particularly deer, may also be equally important in explaining changes in patterns of tick abundance and activity [23].

A central problem associated with understanding changing arthropod-borne disease patterns is that systematic surveillance in animals is not routinely undertaken [24]. The cost and complexity of this monitoring is high because vector and pathogen prevalence are often relatively low and large samples sizes are required for meaningful results. Surveillance programmes often rely on passive reporting, which may render them subject to significant levels of spatial and temporal bias. Nevertheless, systematic surveillance is essential to allow detection of changes in the distribution of arthropod vectors and arthropodborne diseases, particularly because subtle changes at the early stages of an epidemic curve are hard to spot. Routine surveillance is also needed to allow informed risk analysis and the evaluation of the potential spread to new areas or the new introduction of exotic species or diseases [24-26]. This necessitates clear and exhaustive knowledge of the distribution of arthropod vectors and associated vectorborne diseases in different areas [1].

The aim of the work described here therefore was to undertake a national survey of tick abundance on dogs presented to veterinary practices in the UK and to provide a comprehensive spatial understanding of the distribution and species abundance against which future changes could be compared. This study also aimed to evaluate an approach to large-scale surveillance that allows relatively cost- and time-effective extensive data collection.

\section{Methods}

Veterinary practices from throughout the UK were recruited largely through an intensive media and communication initiative, designed to raise awareness of ticks and tick-borne disease amongst veterinarians and the general public. The campaign, launched in March 2015, used an intense period of radio, television, print and social media to highlight the role of ticks as vectors of canine disease in the UK. Interested veterinary practices were then able to register their interest by emailing a contact name and their practice details. Once enrolled, they were sent a pack which contained 40 questionnaires, stamped addressed envelopes, a tick removal hook, specimen tubes and protocols. The protocol asked registered veterinary practices to examine five different dogs for ticks each week, for a total of 8 weeks, using a specified standard grooming procedure and then complete a questionnaire relating to the clinical and travel history of each dog. Veterinarians were asked to ensure that the dogs selected for inspection were a random cross-section of animals brought into the surgery for routine procedures such as vaccination and were not those known to be carrying ticks when selected, but no formal randomisation procedure was included in the protocol.

The examination protocol for included dogs required first checking the head for ticks. Special attention was given to the ears, carefully checking the pinnae and inside the external ear canal. The dog was then checked on the neck and chest area, legs, armpits and interdigital spaces. After that the dog's hair, from head to tail, was checked manually using sufficient pressure to detect small lumps. Finally, a louse or flea comb was used to part the hair along the length of the body. The examination was estimated to take an average of $5 \mathrm{~min}$ per dog. All attached ticks were removed using a tick hook or forceps, placed in a tube labelled with the dog's name and inspection date and stored in a freezer at $-20{ }^{\circ} \mathrm{C}$. Each week stored ticks along with the completed questionnaires were posted to the investigators. The instructions sent to each registered veterinary practice stressed the importance of completing and sending questionnaires for dogs that were found not to have ticks, to allow a true prevalence figure to be calculated.

Each tick sample received by the investigators was given a unique identification number and placed in freezer at $-20{ }^{\circ} \mathrm{C}$ pending analysis. Subsequently, ticks were identified to species, life-cycle stage and sex using a range of keys [27-29] and a sub-sample of identifications cross-checked by an independent investigator. The questionnaire data were entered into an Excel (Microsoft) worksheet.

The history and sex, breed and age of each dog were recorded. To determine any effect of sex on tick attachment, four categories were considered: male, female, male neutered and female neutered. For the effect of breed, the dogs were categorised following Kennel Club 
classifications: gundogs, hounds, pastoral, terriers, toy, utility and working, plus mongrels and crossbreds. To assess any effects of age, dogs were divided into five classes: less than 1 year-of-age, 1 to 3,4 to 6,7 to 10 and any of greater than 10 years-of-age. Each dog's travel history and any history of visits to kennels were also recorded. The data were subjected to binary logistic regression using SPSS (version 23). The distribution of the participating veterinary practices, dogs and various tick species were mapped using QGIS (version 2.8.1) using the practice or owner's postcodes.

\section{Results}

A total of 1000 and 94 veterinary practices from across the UK participated in the 16 week study (Fig. 1); in this time 12,096 dogs were examined for each of which a completed questionnaires was submitted. 6555 tick samples were also submitted, of which 5915 were identified, while 640 were too damaged to allow identification. The median number of ticks per sample was 1, although the maximum number reported on an individual dog was about 200. Of the tick samples received, $98.7 \%$ were adults alone, $0.83 \%$ were nymphs alone and $0.11 \%$ were larvae alone. All the remaining samples were mixed stage. The nymphs and adults were identified to species, the very small numbers of larvae received were not identified. Almost all ticks were semi- or fully-engorged.

\section{Species abundance and distributions}

Amongst dogs that had not travelled outside the UK, $89.2 \%$ of those that had ticks were infected by I. ricinus and $9.8 \%$ by Ixodes hexagonus Leach (Table 1). Both species were widely distributed throughout the UK (Fig. 2a, b). Smaller numbers of Ixodes canisuga Johnston were recorded, less than $0.78 \%$ of the dogs were infected by this species, and these tended to have a more southerly distribution in England and Wales with none submitted from the northern half of Scotland (Fig. 2c). Ten dogs

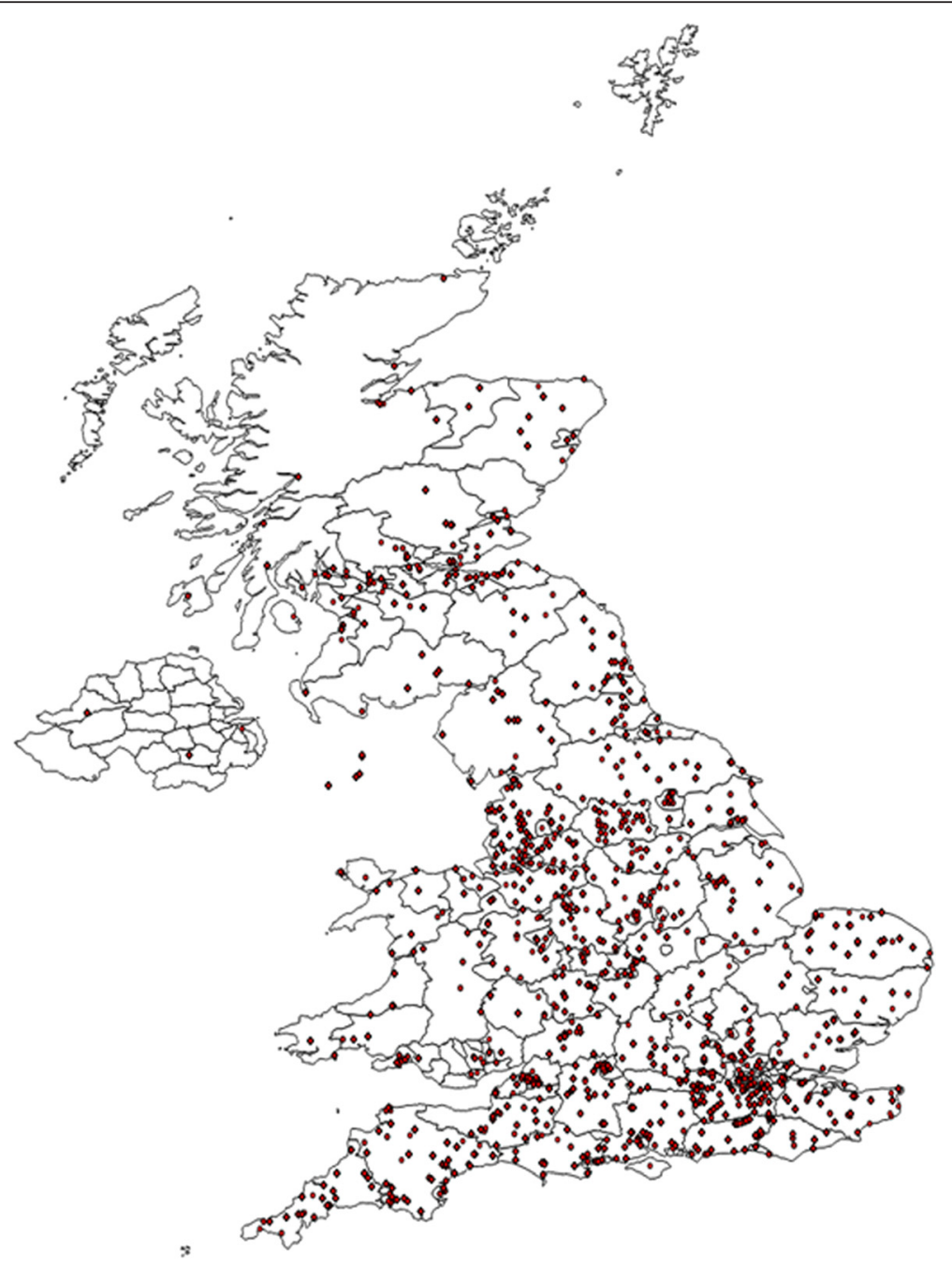

Fig. 1 Distribution of the 1094 veterinary practices that participated in the UK survey for ticks on dogs over 16 weeks (March to July) in 2015 
Table 1 The number and percentage of dogs that had not travelled outside the UK in the previous 2 weeks, infested by each species of tick as submitted by veterinary practices that participated in the UK survey

\begin{tabular}{lll}
\hline Tick species & Number of dogs & Percentage \\
\hline Ixodes ricinus & 5236 & 89.2 \\
Ixodes hexagonus & 577 & 9.8 \\
Ixodes canisuga & 46 & 0.78 \\
Haemaphysalis punctata & 3 & 0.05 \\
Dermacentor reticulatus & 10 & 0.17 \\
$\begin{array}{l}\text { Total number of dogs infested } \\
\text { by endemic ticks }\end{array}$ & 5872 & \\
\hline
\end{tabular}

a

d
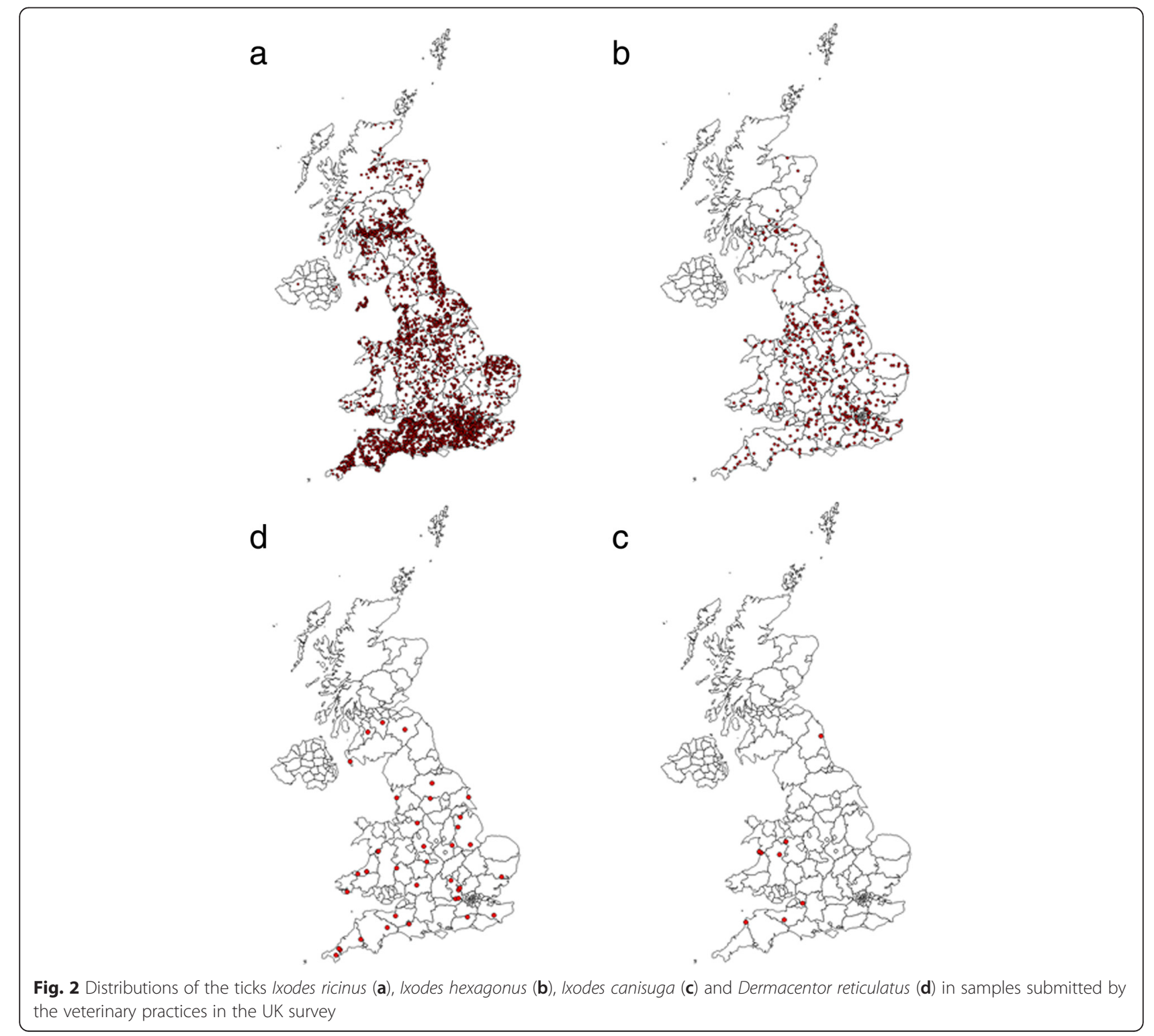

were found to be infected with $D$. reticulatus, largely from populations in western Wales and south-west England (Fig. 2d). The one case recorded in north-east England, was from a dog known to have travelled to Wales in the previous week. Three dogs were infected by Haemaphysalis punctata Canestrini \& Fanzago; all were from one specific location in south east England (not plotted). Five dogs with mixed species infestations were detected, in three of these cases I. ricinus was found along with I. hexagonus, whereas in other two I. ricinus was found with $I$. canisuga and D. reticulatus.

Fifty-six dogs had travelled outside the UK in the previous 2 weeks (Table 2); 29 were infected with $I$. ricinus. Thirteen were infected by Rhipicephalus sanguineus Latrille all of which were found on animals that had entered from the Mediterranean region (predominantly 
Table 2 Amongst the samples submitted by veterinary practices, 56 dogs had travelled outside the UK in the previous 2 weeks, 43 of which were infested by one of three species of tick

\begin{tabular}{ll}
\hline Tick species & $\begin{array}{l}\text { Number of travelled } \\
\text { dogs infested (\%) }\end{array}$ \\
\hline Ixodes ricinus & $29(67.4)$ \\
Dermacentor variabilis & $1(2.3)$ \\
Rhipicephalus sanguineus & $13(30.2)$ \\
Total number with ticks & 43 \\
\hline
\end{tabular}

Cyprus and Spain). One dog with Dermacentor variabilis (Say) was detected, on an animal imported from the USA.

\section{Host associations and risk factors}

Logistic regression was used to consider the effects of various risk factors on the likelihood that dogs may get bitten by ticks. This analysis showed that breed, neutered status and age significantly predicted the likelihood of dogs having ticks, but visits to kennels and exposure to different habitats did not (Table 3). Pastoral and Gundogs were the breeds most likely to have ticks $\left(R^{2}=0.037, d f 9,17, P<0.001\right)$; neutered male and female dogs were at lower risk of tick infestation than male or female unneutered dogs $\left(R^{2}=0.037, d f_{3,17}\right.$, $P<0.001)$. All age groups were significantly more likely to have ticks than dogs of 1 year-old or below $\left(R^{2}=0.037, d f_{5,17}, P<0.001\right)$.

\section{Prevalence of tick attachment}

Prevalence estimation requires random selection of dogs without bias towards dogs known to have attached ticks. However, while many participating veterinary practices,

Table 3 Significance, odds ratios and $95 \%$ confidence intervals (Cls) of the logistic regression between presence and absence of ticks and an array of significant tick risk factors

\begin{tabular}{|c|c|c|c|}
\hline & Significance & Odds ratio & $95 \% \mathrm{Cl}$ \\
\hline \multicolumn{4}{|l|}{ Breed type } \\
\hline Pastoral & 0.009 & 1.809 & $1.162-2.817$ \\
\hline Gundogs & 0.026 & 1.619 & $1.060-2.471$ \\
\hline \multicolumn{4}{|l|}{ Dog sex } \\
\hline Male neutered & $<0.0001$ & 0.638 & $0.553-0.736$ \\
\hline Female neutered & $<0.0001$ & 0.570 & $0.494-0.659$ \\
\hline \multicolumn{4}{|l|}{ Dog age } \\
\hline 1 to 3 years & $<0.0001$ & 1.400 & $1.184-1.655$ \\
\hline 3 to 6 years & 0.001 & 1.331 & $1.128-1.571$ \\
\hline 6 to 10 years & 0.036 & 1.202 & $1.012-1.427$ \\
\hline Above 10 years & 0.014 & 1.288 & $1.052-1.577$ \\
\hline
\end{tabular}

Hosmer-Lemeshow test: $X^{2}=2.117, d f=8, P=0.977$ as expected, sent more negative questionnaire reports than positive, some veterinary practices sent questionnaire reports only from infested dogs. It is therefore likely that these practices misunderstood the study protocol and only submitted reports when ticks were found. All data submitted from practices that sent only positive samples from any single week in which it participated in the survey were not included in the prevalence analysis. Data from practices that submitted reports from three or fewer dogs any week were also removed, since it was considered unlikely that any practice would see fewer than three dogs in a week. This removal of inspection records from practices where miss- or overreporting was suspected, resulted in the removal of 4994 dogs. Following this, the total number of dog records remaining was 7102 and of these 2182 of the dogs had ticks. The prevalence of ticks on dogs over the entire 16-week period was thus $30.7 \%$ (95\% exact binomial confidence interval \pm 0.011 ) (Table 4 ). Calculation of the prevalence over each four-week period of the study showed little variation, with a range of 28-32\% (Table 4). The prevalence data were mapped by county to give a visual indication of geographical differences (Fig. 3). Where there were small sample sizes from any one county, counties were merged to give a minimum sample of 200 cases per reporting area and a pooled prevalence was plotted. Prevalence was then mapped on a relative scale of 1 to 5 . The data show that the highest prevalence of tick infestation are in south west England, East Anglia and Scotland, but are also high throughout most of central and northern England.

\section{Discussion}

The three tick species most commonly encountered on humans, livestock and companion animals in the UK are Ixodes ricinus, $I$. hexagonus and I. canisuga; of these, I. ricinus is the most widely distributed and poses the greatest biting risk [16]. This species is the known principal vector for Lyme borreliosis and Anaplasma, louping ill virus (LIV) and various species of Babesia

Table 4 The number of dogs inspected and the number found to have at least one tick attached in each 4 week period of the 16 week study, in samples submitted by veterinary practices in the UK survey

\begin{tabular}{lllcc}
\hline $\begin{array}{l}\text { Time period } \\
\text { (weeks) }\end{array}$ & $\begin{array}{l}\text { Number } \\
\text { of dogs }\end{array}$ & $\begin{array}{l}\text { Number of tick } \\
\text { infested dogs }\end{array}$ & $\begin{array}{l}\text { Prevalence } \\
(\%)\end{array}$ & $\begin{array}{l}95 \% \text { confidence } \\
\text { interval }\end{array}$ \\
\hline $1-4$ & 287 & 81 & 28.2 & 0.052 \\
$5-8$ & 1784 & 503 & 28.2 & 0.021 \\
$9-12$ & 2938 & 959 & 32.6 & 0.017 \\
$13-16$ & 2093 & 639 & 30.5 & 0.019 \\
$1-16$ & 7102 & 2182 & 30.7 & 0.011 \\
\hline
\end{tabular}

The estimated percentage prevalence with exact binomial $95 \%$ confidence intervals are also presented 


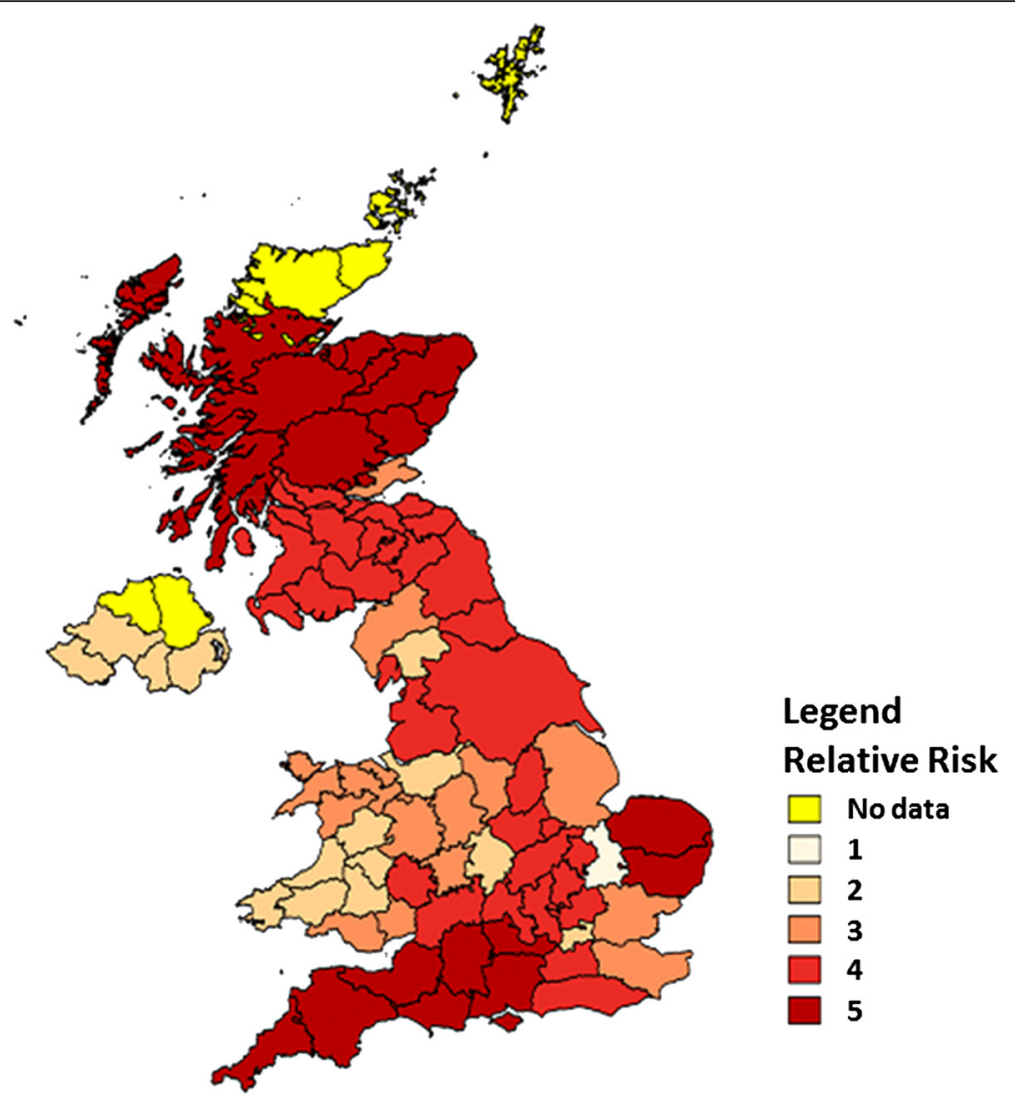

Fig. 3 The relative risk of tick attachment on dogs on a scale of 1 to 5, based on the prevalence of ticks found in different regions of the UK in samples submitted by the veterinary practices in the UK survey

$[2,6,30]$. In mainland Europe I. ricinus also acts as a vector of tick-borne encephalitis (TBE) in humans and Ehrlichia canis; the latter has been recorded recently for the first time in a non-travelled dog in the UK [31]. In a previous study, based on 56 veterinary practices and 280 animals in the UK, $52 \%$ of dogs and cats with ticks carried $I$. ricinus, $39 \%$ carried $I$. hexagonus, and $11 \%$ were infested with $I$. canisuga [32]. More recently, a study involving 180 veterinary practices found that $72.1 \%$ of tick infestations on domestic dogs were due to I. ricinus, $22 \%$ due to $I$. hexagonus and $6 \%$ due to I. canisuga [17]. In the present study, data collected from over 1000 veterinary practices and 12,000 dogs showed that the proportion of I. ricinus was considerably higher than in earlier studies at $89 \%$, while I. hexagonus was the second most abundant species $(10 \%)$ and $I$. canisuga was relatively rare $(1 \%)$. Despite differences from study to study, the pattern of abundance of the three species appears relatively consistent; variation may be due to differences in time of year, geographic focus or the sample population examined.

The abundance of each tick species is strongly determined by differences in climate, host availability and vegetation cover, which affects microclimate. Ixodes ricinus is most commonly associated with woodland and moorland habitats, although high densities may also be found in urban recreational spaces [33] as with $I$. hexagonus [32]. In the present study, both species were found throughout the UK as far north as Scotland. In contrast, I. canisuga has been reported as being more commonly found in boarding kennel environments [27], although infestation by $I$. canisuga was seen here in dogs that had no previous exposure to kennels, as has been reported previously [32]. Hence this species evidently lives in association with wildlife hosts, such as mustelids [27]. As seen in previous studies [17], I. canisuga appeared to have a more strongly southerly distribution in the current study.

Risk factors associated with tick attachment are highly inconsistent between studies. Dog breed, sex, age and neutered status were not found to be significant predictors of tick infestation [34]. Earlier work [17] found that hound, toy and utility breeds and neutered dogs had a lower probability of tick attachment, but reported no significant effect of sex. In the current study, older dogs were more likely to have ticks than dogs of 1 year-of-age or below, pastoral and gundogs were at higher risk than other breeds while neutered dogs were at lower risk than 
unneutered dogs. No effect of sex was detected. It is possible that the highly variable results between studies are due to the fact that tick attachment rate has been shown to be most strongly correlated with exposure rather than any dog physiological or phenotypic characteristics, as demonstrated by Jennet et al. [34]. Surprisingly, dogs that were restricted to urban habitats were no less likely to have ticks that dogs exposed to more rural habitats. This corresponds with the growing number of reports of high numbers of ticks in urban environments $[32,33]$. Almost all the ticks found were adults; only 76 were immatures. It is relatively likely that dogs are bitten by a greater proportion of immatures than is apparent from the data presented here, but their absence in the samples received strongly suggests that this life-cycle stage is undetected in clinical examination.

The results of this study show that a large-scale, costeffective national tick prevalence assessment can be conducted using voluntary enrolment. Publicity and media interest were pivotal to the approach, generating enthusiasm amongst the participating veterinary surgeons. However, there were evident limitations; veterinarians who signed up agreed to inspect a given number of dogs per week and these were to be a random selection of otherwise healthy animals brought to the surgery. In the study reported by Smith et al. [17] which used a similar protocol, 60 veterinary practices participated in tick collection at any one time and incoming samples were monitored closely and veterinary practices were contacted individually by telephone when unexpected patterns were detected to ensure that the protocols were rigorously followed. Given the number of veterinary practices that participated in the current study, this approach could not be adopted and more than half of participating practices sent too few or only positive samples for at least 1 week during their participation. Furthermore, over 200 ticks were sent from cats (plus samples from humans and birds). On the other hand, the very large sample size meant that a more rigorous post-hoc approach could be taken to exclude specific categories of return.

After exclusion of returns where only cases from dogs positive for tick infestation were submitted, an overall attachment prevalence on dogs of $30 \%$ was recorded over the 16-week sample period. There was little change in this prevalence figure when sub-divided into 4-week periods (range $28-32 \%$ ). This attachment rate is still relatively high; in the study by Smith et al. [30] a median frequency of infestation of $14.9 \%$ was reported, but $19 \%$ of veterinary practices found no ticks and $14.6 \%$ reported that more than $50 \%$ of the dogs inspected carried ticks. In the present study, it is likely that the veterinarians who enrolled were those with the greatest interest in ticks and tick-borne disease or were in practices with a known history of tick problems amongst their clients resulting in over-reporting. Nevertheless, if it is assumed that over-reporting has no regional bias, the data can be used on a relative scale to compare geographical differences in relative risk. Scotland, south-west England and East Anglia showed the highest regional prevalence, although prevalence was also high throughout central and northern England. The relatively low prevalence in Wales was perhaps surprising, given the vegetation and climatic requirements, particularly of I. ricinus.

The distribution of $D$. reticulatus is of particular current interest because it is the primary vector of canine babesiosis. Much like I. ricinus, D. reticulatus is also known to have extended its distribution northwards through mainland Europe [13, 15, 35]. Historical records show that this tick has been found in the UK for over 100 years (http://data.nbn.org.uk). However, in recent years it has become more widely established in southern England and Wales $[17,36]$. There are now known to be at least four established predominantly coastal populations: west Wales, south Devon, north Devon and Essex $[16,36]$. Other populations may as yet be undiscovered. Here, samples were found in Wales and south-west England, confirming established distribution pattern of this species in these areas, but no cases were submitted from the Essex population. In the UK, there have been an increasing number of cases of babesiosis in dogs that have travelled to Europe [37], with other cases probably unreported [38]. In March 2016, a cluster of cases of canine babesiosis, due to B. canis, was reported in Essex in nontravelled dogs confirming that this pathogen is now well established in the UK [39]. This outbreak highlights the urgent need for an improved understanding of the ecology and behaviour of the vector, and in particular, an understanding of its distribution and mechanism(s) of dispersal.

Fifty-six dogs were known to have travelled outside the UK in the 2 weeks prior to their inclusion in the study and 43 of these were found to be carrying attached ticks, predominantly I. ricinus. The 13 cases of the tick, $R$. sanguineus, that were detected in travelled dogs, highlight the concern regarding the import and potential establishment of this species following changes to the pet passport scheme in 2012 which had previously required dogs entering the UK to be treated against ticks [26]. This species has now been shown to have overwintered in the UK in at least two locations [26]. The data clearly emphasise the importance of appropriate treatment against ticks for dogs that are travelling and the persistent threat of introduction and establishment of nonendemic ticks and their pathogens into the UK.

\section{Conclusions}

This study has shown how very large samples can be generated through voluntary participation of veterinary 
surgeries following a high profile media and communication campaign. However, despite a clear protocol for participants, this approach resulted in a prevalence of tick infestation that is considerably higher than seen in previous studies, probably as a result of over-reporting. Nevertheless, the data presented provide a comprehensive spatial understanding of tick distribution and species abundance against which future changes can be compared while the relative prevalence maps show the highest rates in Scotland and south-west England, providing a valuable guide to tick-bite risk in the UK.

\section{Acknowledgements}

We are grateful to a large number of undergraduate students who assisted with management of tick samples and with digitising tick records: Beth Savagar, Saloni Bhuptani, Kitty Sherwood, Sarina Saddiq and Zoe McLoughlin, Claire Le Roy, Mathilde Fayolle-Baussian and Charlotte Dumas. Charilaos Pylidi advised in mapping. We are particularly grateful to Keyleigh Hansford at Public Health England for confirming tick identifications. We would also thank all the veterinary practices who participated in this study.

\section{Funding}

SA was supported by a University of Bristol Zutshi-Smith PhD scholarship. The study was designed and the data analysed and interpreted by SA and RW. MSD Animal Health contributed to consumables costs, engaged Dr Susan McKay (Companion Consultancy) to handle the logistics of enrolling and registering veterinary practices and Liz Peplow (Sourced Communications Ltd.) to manage the media campaign. The MSD Animal Health sales team also helped to recruit participating veterinary practices. Veterinarians did not receive payment for their participation.

\section{Availability of data and materials}

The datasets supporting the conclusions of this article are included within the article.

\section{Authors' contributions}

SA was study investigator, coordinated and supervised the labour force, data collection and undertook statistical analysis; RW was study director; RW and $\mathrm{HN}$ assisted in the design and management of the study and interpretation of data; ST and CH provided advice, laboratory support and critically reviewed the manuscript; all authors reviewed and approved the final manuscript.

\section{Competing interests}

SA has no competing interests; RW, ST and CH have had research funded by a range of pharmaceutical companies and animal health charities; RW is a director of AgriEnt Ltd.; HN is an employee of MSD Animal Health.

\section{Consent for publication}

Not applicable.

\section{Ethics approval and consent to participate}

This work was carried out with the approval of the University of Bristol ethics committee, UIN: UB/15/008.

\footnotetext{
Author details

${ }^{1}$ Veterinary Parasitology and Ecology Group, School of Biological Sciences, Life Sciences Building, University of Bristol, Bristol, UK. ${ }^{2}$ Molecular Diagnostic Unit, Langford Veterinary Services and School of Veterinary Sciences, University of Bristol, Bristol, UK. ${ }^{3}$ MSD Animal Health, Walton Manor, Walton, Milton Keynes, UK.
}

Received: 23 May 2016 Accepted: 29 June 2016

Published online: 07 July 2016

\section{References}

1. Otranto D, Wall R. New strategies for the control of arthropod vectors of disease in dogs and cats. Med Vet Entomol. 2008;22:219-302.
2. Gray JS. The development and seasonal activity of the tick /xodes ricinus: a vector of Lyme borreliosis. Rev Med Vet Entomol. 1991;79:323-33.

3. Korotkov Y, Kozlova T, Kozlovskaya L. Observations on changes in abundance of questing Ixodes ricinus, castor bean tick, over a 35-year period in the eastern part of its range (Russia, Tula region). Med Vet Entomol. 2015;29:129-36.

4. Daniel M, Danielová V, Kríz B, Jirsa A, Nozicka J. Shift of the tick Ixodes ricinus and tick-borne encephalitis to higher altitudes in central Europe. Eur J Clin Microbiol Inf Dis. 2003;22:327-8.

5. Kirby AD, Smith AA, Benton TG, Hudson PJ. Rising burden of immature sheep ticks (Ixodes ricinus) on red grouse (Lagopus lagopus scoticus) chicks in the Scottish uplands. Med Vet Entomol. 2004;18:67-70.

6. Pietzsch ME, Medlock JM, Jones L, Avenell D, Abbott J, Harding P, Leach S. Distribution of Ixodes ricinus in the British Isles: investigation of historical records. Med Vet Entomol. 2005;19:306-14.

7. Jore $S$, Viljugrein $H$, Hofshagen M, Brun-Hansen $H$, Kristoffersen $A B$, Nygard K, et al. Multi-source analysis reveals latitudinal and altitudinal shifts in range of Ixodes ricinus at its northern distribution limit. Parasit Vectors. 2011:4:84-95.

8. Danielová V, Rudenko N, Daniel M, Holubová J, Materna J, Golovchenko M, Schwarzová L. Extension of Ixodes ricinus ticks and agents of tick-borne diseases to mountain areas in the Czech Republic. I J Med Microbiol. 2006;296:48-53.

9. Tälleklint L, Jaenson TGT. Increasing geographical distribution and density of Ixodes ricinus (Acari: Ixodidae) in Central and Northern Sweden. J Med Entomol. 1998;35:521-6.

10. Lindgren E, Tälleklint L, Polfeldt T. Impact of climatic change on the northern latitude limit and population density of the disease-transmitting European tick Ixodes ricinus. Env Health Persp. 2000;108:119-23.

11. Scharlemann JPW, Johnson PJ, Smith AA, Macdonald DW, Randolph SE. Trends in ixodid tick abundance and distribution in Great Britain. Med Vet Entomol. 2008:22:238-47.

12. Zygner W, Górski P, Wedrychowicz H. New localities of Dermacentor reticulatus tick (vector of Babesia canis canis) in central and eastern Poland. Pol J Vet Sci. 2009;12:549-55.

13. Beugnet $F$, Marié JL. Emerging arthropod-borne diseases of companion animals in Europe. Vet Parasitol. 2009;163:298-305.

14. Dautel H, Dippel C, Kämmer D, Werkhausen A, Kahl O. Winter activity of Ixodes ricinus in a Berlin forest. I J Med Microbiol. 2008;298:50-4.

15. Matjila TP, Nijhof AM, Taoufik A, Houwers D, Teske E, Penzhorn BL, et al. Autochthonous canine babesiosis in The Netherlands. Vet Parasitol. 2005:131:23-9.

16. Jameson LJ, Medlock JM. Tick surveillance in Great Britain. Vector-borne Zoonotic Dis. 2011;11:403-12.

17. Smith F, Ballantyne R, Morgan E, Wall R. The incidence of tick infestation on domestic dogs in the UK. Med Vet Entomol. 2011;25:377-84.

18. Lindgren $E$, Gustafson R. Tick-borne encephalitis in Sweden and climate change. Lancet. 2001;358:16-8.

19. Daniel M, Křřž B, Danielová V, Beneš Č. Sudden increase in tick-borne encephalitis cases in the Czech Republic, 2006. I J Med Microbiol. 2008:298:81-7.

20. Parmesan C, Yohe G. A globally coherent fingerprint of climate change impacts across natural systems. Nature. 2003;21:37-42.

21. IPCC Annex I. Atlas of global and regional climate projections. Climate change 2013: the physical science basis. In: van Oldenborgh GJ, Collins M, Arblaster J, Christensen JH, Marotzke J, Power SB, et al., editors. Contribution of working group I to the fifth assessment report of the intergovernmental panel on climate change. Cambridge: Cambridge University Press; 2013.

22. Carpenter S, Wilson A, Barber J, Veronesi E, Mellor P, Venter G, Gubbins S. Temperature dependence of the extrinsic incubation period of orbiviruses in Culicoides biting midges. PLoS One. 2011;6:e27987.

23. Randolph SE. Evidence that climate change has caused "emergence" of tickborne diseases in Europe? I J Med Microbiol. 2004;293:5-15.

24. Wall R. Ectoparasites: future challenges in a changing world. Vet Parasitol. 2007;148:62-74

25. Randolph SE, Rogers DJ. The arrival, establishment and spread of exotic diseases: patterns and predictions. Nature Rev Microbiol. 2010;8:361-71.

26. Hansford KM, Pietzsch ME, Cull B, Medlock JM, Wall R. Overwintering of the brown dog tick in residential properties in England - raising awareness. Vet Rec. 2015;177:156.

27. Arthur DR. British ticks. Wallingford: CABI; 1963. p. 218. 
28. Hillyard, PD, Ticks of North-west Europe. Synopses of the British Fauna 52;1996. Field Studies Council, Shrewsbury.

29. Walker A, Bouattour A, Camicas J-L, Estrada-Peña A, Horak IG, Latif AA, et al. Ticks of domestic animals in Africa: a guide to identification of species. UK: Bioscience Reports Edinburgh; 2014.

30. Smith FD, Ellse L, Wall R. Prevalence of Babesia and Anaplasma in ticks infesting dogs in Great Britain. Vet Parasitol. 2013;198:18-23.

31. Wilson HE, Mugford AR, Humm KR, Kellett-Gregory LM. Ehrlichia canis infection in a dog with no history of travel outside the United Kingdom. J Small Anim Pract. 2013;54:425-7.

32. Ogden NH, Cripps P, Davison CC, Owen G, Parry JM, Timms BJ, Forbes AB The ixodid tick species attaching to domestic dogs and cats in Great Britain and Ireland. Med Vet Entomol. 2000;14:332-8.

33. Nelson C, Banks S, Jeffries CL, Walker T, Logan JG. Tick abundances in South London parks and the potential risk for Lyme borreliosis to the general public. Med Vet Entomol. 2015;29:448-52.

34. Jennett $A L$, Smith FD, Wall R. Tick infestation risk for dogs in a peri-urban park. Parasit Vectors. 2013;6:358

35. Sréter T, Széll Z, Varga I. Spatial distribution of Dermacentor reticulatus and Ixodes ricinus in Hungary: evidence for change? Vet Parasitol. 2005;128:347-51.

36. Medlock JM, Jameson $\amalg$, Phipps LP. Status of Dermacentor reticulatus in the UK. Vet Rec. 2011;168:386-7.

37. Holm LP, Kerr MG, Trees AJ, McGarry JW, Munro ER, Shaw SE. Fatal babesiosis in an untravelled British dog. Vet Rec. 2006;159:179-80.

38. Tasker S. Exotic diseases - a growing concern? J Small Anim Pract. 2013;54:393-4.

39. Phipps LP, Fernandez De Marco MDM, Hernández-Triana LM, Johnson N, et al. Babesia canis detected in dogs and associated ticks from Essex. Vet Rec. 2016;178:243-4.

\section{Submit your next manuscript to BioMed Central and we will help you at every step:}

- We accept pre-submission inquiries

- Our selector tool helps you to find the most relevant journal

- We provide round the clock customer support

- Convenient online submission

- Thorough peer review

- Inclusion in PubMed and all major indexing services

- Maximum visibility for your research

Submit your manuscript at www.biomedcentral.com/submit 